\title{
The association between maternal exposure to secondhand smoke during pregnancy and their children's cerebral palsy, Shandong, China
}

\author{
Songtao Ren ${ }^{1,2,3}$, Shaohua Xie ${ }^{4}$, Xuri Li ${ }^{5}$, Guofeng Li ${ }^{6}$, Yan Wang ${ }^{7}$, Weidong Liu' ${ }^{1}$ Li Wang $2,3,3,9$
}

\begin{abstract}
INTRODUCTION Tobacco use poses a threat to the health of pregnant women and their children. Our study assessed the association between maternal exposure to secondhand smoke (SHS) during pregnancy and children's cerebral palsy (CP) in Shandong, China.

METHODS In our observational study, 5067 mother-child pairs were included from Shandong Province, China. Mothers filled in questionnaires about exposure to SHS during pregnancy. Statistical analysis and logistic regression models were built in $\mathrm{R}$ program to estimate the association in adjusted odds ratio (AOR) between SHS exposure during pregnancy and risk of children's CP, after adjustment for potential confounders including delivery mode and baby's birthweight.

RESULTS Exposure to SHS was noted among 3663 (72.3\%) of the 5067 non-smoking mothers during their pregnancy. Of the $239 \mathrm{CP}$ children within the study, $192(80.3 \%)$ were exposed to SHS during pregnancy. Children born to mothers exposed to SHS during pregnancy had a higher risk of $\mathrm{CP}(\mathrm{AOR}=1.44 ; 95 \% \mathrm{CI}$ : 1.02-2.04) than those born to non-exposed mothers, the risk increased by exposure time in the logistic regression model. The association between SHS exposure during pregnancy and CP children remained significant when adjusting for delivery mode and infant's birthweight due to their significant association with CP, with an AOR of 1.46 (95\% CI: 1.13-1.91) for 1-4 days/week and 1.63 (95\% CI: 1.22-2.01) for 5-7 days/week exposure to SHS.
\end{abstract}

CONCLUSIONS Our study suggests that maternal exposure to secondhand smoke during pregnancy is associated with children's CP. Future preventive interventions of CP should include strategies that target the antenatal women who are exposed to SHS.

\author{
AFFILIATION \\ 1 Department of Neurosurgery, Liaocheng \\ People's Hospital, Liaocheng, People's \\ Republic of China \\ 2 School of Medicine, Shandong University, \\ Jinan, People's Republic of China \\ 3 Medical College, Liaocheng University, \\ Liaocheng, People's Republic of China \\ 4 Department of Pediatrics, Liaocheng \\ People's Hospital, Liaocheng, People's \\ Republic of China \\ 5 Department of Gynecology and Obstetrics, \\ Qingdao Hiser Medical Group, Qingdao, \\ People's Republic of China \\ 6 Department of Physical Medicine, \\ Liaocheng No. 4 People's Hospital, \\ Liaocheng, People's Republic of China \\ 7 Department of Medical Record, Liaocheng \\ No. 4 People's Hospital, Liaocheng, People's \\ Republic of China \\ 8 Department of Gynecology, Liaocheng \\ People's Hospital, Liaocheng, People's \\ Republic of China \\ 9 Metabolism Group, Research Unit of \\ Molecular Epidemiology, Institute of \\ Epidemiology, Helmholtz Zentrum München, \\ German Research Center for Environmental \\ Health, Munich, Germany
}

\section{CORRESPONDENCE TO}

Li Wang. Department of Gynecology, Liaocheng People's Hospital, Dongchang West Street 67, Liaocheng City 252000, Shandong Province, People's Republic of China.E-mail: wlrst@126.com

\section{KEYWORDS}

pregnancy, secondhand smoke, cerebral palsy

Received: 10 March 2020

Revised: 13 August 2020

Accepted: 25 September 2020

\section{INTRODUCTION}

The use of tobacco is considered as a threat to pregnant women and their children's health ${ }^{1}$. Exposure to secondhand smoke (SHS) is associated with cardiovascular or pulmonary diseases, malignancy, and numerous other health problems ${ }^{2}$. It has been established that passive smoking during pregnancy may lead to health risks for both the mother and 
child ${ }^{3}$, including pregnancy complications such as pre-eclampsia, and poor fetal outcomes ${ }^{4,5}$ such as low birthweight, premature birth etc. The prevalence of childhood asthma ${ }^{6}$, fetal dysplasia and nervous system diseases ${ }^{7}$ is also noted to be higher in children whose mothers were exposed to SHS during pregnancy.

Cerebral palsy (CP) is a group of permanent disorders that cause activity limitation including movement and posture development. It can be attributed to non-progressive disturbances that occurred in the developing fetal brain. Motor disorders of cerebral palsy are often accompanied with perception, sensational disturbances, communication, cognition and behavior, by secondary musculoskeletal problems or by epilepsy ${ }^{8}$. As the most common pediatric motor disability, it is not only a significant lifetime disability for children but also linked to a shortened life expectancy ${ }^{9}$.

As CP is a syndrome that partly is due to a lesion that may have occurred in the developing brain during pregnancy - a period of important neurodevelopment - SHS exposure may be a risk factor for early neurological dysplasia. In our study, the association between SHS exposure during pregnancy and children's CP was assessed.

\section{METHODS}

\section{Participants}

This observational study was carried out in Public Health Communities in Shandong Province, China. We collected information on children with CP who accepted treatment in hospitals or were newly diagnosed during the screening. Healthy children were selected by public health communities' physical examinations from 32 communities. In total, 6576 mother-child pairs who received treatment at our hospitals and attended health checkups at public health community centers were selected. As we were interested in the role of SHS exposure during pregnancy as a risk factor for unexplained CP, we excluded children who were diagnosed with another central nervous system anomaly or infection, a genetic or chromosomal abnormality, or traumatic brain injury, which may substantially have increased the risk of CP. Singleton births were also limited in our analysis. Subsequently, 5655 mother-child pairs completed our questionnaires. There were 337 participants with missing information of SHS exposure and they were excluded from the current analysis, while 5318 participants were included for final analysis, of which 5067 were non-smokers and were included. The study protocol was approved by the ethics committee of Liaocheng People's Hospital, Shandong Provincial Hospital Affiliated to Shandong University, Qingdao Hiser Medical Group, and by the Liaocheng Public Health Communities. All participants gave written informed consent.

\section{Measurements of the exposure variable}

A standardized questionnaire was adapted from the Global Tobacco Adult Survey. In order to describe smoking status during pregnancy, two options were provided to mothers: 'never smoking' and 'ever smoking'. 'Never smokers' were defined as mothers who chose 'never smoking' and reporting no smoking in the past 30 days before pregnancy. SHS exposure was assessed by the question: 'How many days have people smoked near you in one week during your pregnancy?'. The response options for exposure level were: $0,1-4$, and 5-7 days/week. Definition of selfreported SHS exposure was non-smokers inhaled the smoke exhaled from smokers on at least 1 day/week. Women who replied 'none' or '0 day/week' to this question were considered as 'unexposed' and others who chose '1-4 days/week' or '5-7 days/week' were considered as 'exposed'. We also recorded other characteristics including childbearing age, household registration (location), and mode of delivery.

\section{Statistical analysis}

Baseline characteristics were tabulated by children's health status (CP or healthy). Continuous variables were summarized as mean \pm standard deviation (SD). Differences in means for continuous variables among participants for different groups were calculated by Student's t-tests. Categorical variables were presented as proportion (\%) and compared using chi-squared tests. Logistic regression analyses were performed to estimate odds ratios (ORs) and 95\% confidence intervals (95\% CIs) of the association between different levels of exposure to SHS and risk of CP. All the statistical tests were two-tailed, and the cutoff significant level was defined as $\mathrm{p}<0.05$. We performed all statistical analyses in $\mathrm{R}$ (version 3.6.1 https://cran.r-project.org).

\section{RESULTS}

A total of 5318 mother-child pairs were collected 
in our study after excluding those with missing information. In order to restrict our study to the impact of SHS, we excluded the 251 actively smoking mothers from the final analysis, hence 5067 motherchild pairs were analyzed. Table 1 depicts the basic characteristics according to mother-child pairs participating in our study. Those who were exposed to SHS during pregnancy had a vaginal delivery and a lighter birthweight child were more frequent among pairs with CP at the bivariate level.

Table 2 shows the prevalence of SHS and its distribution characteristics according to our survey. The prevalence of SHS exposure of non-smokers during pregnancy was $72.3 \%$. Mothers who did not work and lived in rural areas had a higher prevalence of SHS exposure, younger mothers were more frequently exposed to SHS, and the child's weight at birth was lower than for those who were not exposed $(\mathrm{p}<0.05)$.

Figure 1 shows the distributions of the main characteristics of our study. Of the CP children's mothers, $80.3 \%$ were exposed to SHS during their

Table 1. Characteristics of the study participants according to celebral palsy (CP) status, Shandong, 2017-2019 ( $\mathrm{N}=5067)$

\begin{tabular}{|c|c|c|c|}
\hline Characteristics & $\begin{array}{c}\text { CP } \\
n(\%)\end{array}$ & $\begin{array}{l}\text { No CP } \\
n(\%)\end{array}$ & $p$ \\
\hline \multicolumn{4}{|c|}{$\begin{array}{l}\text { Age of mother during } \\
\text { pregnancy (years) }\end{array}$} \\
\hline mean $\pm S D$ & $30.33 \pm 6.52$ & $30.35 \pm 5.88$ & 0.96 \\
\hline \multicolumn{4}{|l|}{ Occupation } \\
\hline House wife & $123(51.5)$ & $2429(50.3)$ & \multirow{2}{*}{0.778} \\
\hline Employed & $116(48.5)$ & $2399(49.7)$ & \\
\hline \multicolumn{4}{|c|}{ Household registration } \\
\hline Urban & $116(48.5)$ & 2467 (51.1) & \multirow{2}{*}{0.479} \\
\hline Rural & $123(51.5)$ & 2361 (48.9) & \\
\hline \multicolumn{4}{|l|}{ SHS exposure } \\
\hline No & $47(19.7)$ & $1356(28.1)$ & \multirow{2}{*}{0.006} \\
\hline Yes & $192(80.3)$ & 3472 (71.9) & \\
\hline \multicolumn{4}{|l|}{ Delivery mode } \\
\hline Vaginal delivery & $137(57.3)$ & $2367(49.0)$ & \multirow{2}{*}{0.015} \\
\hline Caesarean section & $102(42.7)$ & $2461(51.0)$ & \\
\hline \multicolumn{4}{|l|}{ Infant's sex } \\
\hline Girl & $123(51.5)$ & $2301(47.7)$ & \multirow{2}{*}{0.279} \\
\hline Boy & $116(48.5)$ & $2527(52.3)$ & \\
\hline \multicolumn{4}{|c|}{ Infant's birthweight (kg) } \\
\hline mean $\pm S D$ & $3.05 \pm 0.56$ & $3.19 \pm 0.68$ & 0.0004 \\
\hline
\end{tabular}

pregnancy, including $44.8 \%$ for $1-4$ days/week and $35.5 \%$ for $5-7$ days/week. For the 4828 children without CP, $71.9 \%$ of the mothers reported SHS exposure during pregnancy, including $44.4 \%$ for $1-4$ days/week and $27.5 \%$ for 5-7 days/week (Table 3 ). Women who were exposed to SHS during pregnancy had higher odds of having a baby with $\mathrm{CP}(\mathrm{OR}=1.60$; 95\% CI: 1.5-2.21) than those who were never exposed to SHS, in the crude logistic regression model. The association for SHS exposure during pregnancy and CP children remained significant when adjusting for mode of delivery and infant's birthweight, due to their significant association with CP, with an OR of 1.44 (95\% CI: 1.02-2.04) and AOR of 1.46 (95\% CI: 1.13-1.91) for 1-4 days/week exposure; and an OR of 1.85 (95\% CI: $1.28-2.66$ ) and AOR of 1.63 (95\% CI: 1.22-2.01) for 5-7 days/week exposure. In both crude and adjusted models, pregnant women that were more exposed to SHS had higher odds of having CP babies compared with mothers unexposed to SHS (Table 4).

Table 2. Characteristics of the study participants according to SHS exposure, Shandong, 2017-2019 $(\mathrm{N}=5067)$

\begin{tabular}{|c|c|c|c|}
\hline Characteristics & $\begin{array}{c}\text { Exposed } \\
n(\%)\end{array}$ & $\begin{array}{c}\text { Unexposed } \\
n(\%)\end{array}$ & $p$ \\
\hline \multicolumn{4}{|c|}{$\begin{array}{l}\text { Age of mother during } \\
\text { pregnancy (years) }\end{array}$} \\
\hline mean \pm SD & $29.74 \pm 5.90$ & $31.94 \pm 5.64$ & $<0.001$ \\
\hline \multicolumn{4}{|l|}{ Occupation } \\
\hline House wife & $1997(54.5)$ & 555 (39.6) & \multirow{2}{*}{$<0.001$} \\
\hline Employed & $1667(45.5)$ & $848(60.4)$ & \\
\hline \multicolumn{4}{|c|}{ Household registration } \\
\hline Urban & $1672(45.6)$ & $911(64.9)$ & \multirow{2}{*}{$<0.001$} \\
\hline Rural & $1992(54.4)$ & $492(35.1)$ & \\
\hline \multicolumn{4}{|l|}{ Child status } \\
\hline No CP & $3472(94.8)$ & 1356 (96.7) & \multirow{2}{*}{0.006} \\
\hline $\mathrm{CP}$ & $192(5.2)$ & $47(3.3)$ & \\
\hline \multicolumn{4}{|l|}{ Delivery mode } \\
\hline Vaginal delivery & $1846(50.4)$ & $658(46.9)$ & \multirow{2}{*}{0.029} \\
\hline Caesarean section & $1818(49.6)$ & 745 (53.1) & \\
\hline \multicolumn{4}{|l|}{ Infant's sex } \\
\hline Girl & $1752(47.8)$ & $672(47.9)$ & \multirow{2}{*}{0.984} \\
\hline Boy & 1912 (52.2) & $731(52.1)$ & \\
\hline \multicolumn{4}{|c|}{ Infant's birthweight (kg) } \\
\hline mean $\pm S D$ & $3.12 \pm 0.71$ & $3.34 \pm 0.54$ & $<0.001$ \\
\hline
\end{tabular}


Figure 1. Mosaic of secondhand smoke exposure level, mode of delivery and birthweight

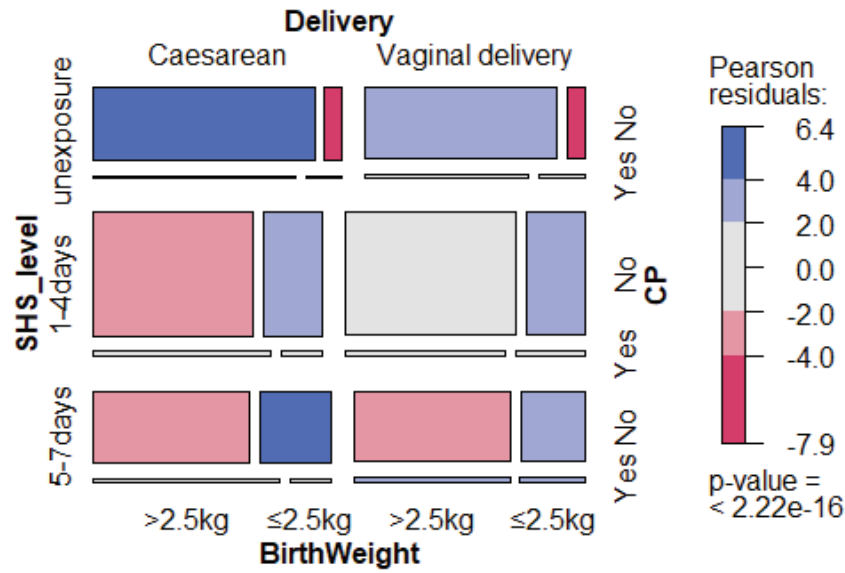

Table 3. Characteristics of the study participants according to different SHS exposure levels (days/week), Shandong, 2017-2019 (N=5067)

\begin{tabular}{|c|c|c|c|c|}
\hline Characteristics & $\begin{array}{c}\text { Unexposed }(n=1403) \\
n(\%)\end{array}$ & $\begin{array}{c}1-4 \text { days }(n=2250) \\
n(\%)\end{array}$ & $\begin{array}{c}5-7 \text { days }(n=1414) \\
n(\%)\end{array}$ & $p$ \\
\hline \multicolumn{5}{|c|}{$\begin{array}{l}\text { Age of mother during } \\
\text { pregnancy (years) }\end{array}$} \\
\hline mean \pm SD & $31.94 \pm 5.64$ & $29.70 \pm 5.62$ & $29.79 \pm 6.31$ & $<0.001$ \\
\hline \multicolumn{5}{|l|}{ Occupation } \\
\hline House wife & $555(39.6)$ & 1097 (48.8) & $900(63.6)$ & \multirow{2}{*}{$<0.001$} \\
\hline Employed & $848(60.4)$ & $1153(51.2)$ & $514(36.4)$ & \\
\hline \multicolumn{5}{|c|}{ Household registration } \\
\hline Urban & $911(64.9)$ & $1155(51.3)$ & $517(37.6)$ & \multirow{2}{*}{$<0.001$} \\
\hline Rural & $492(35.1)$ & $1095(48.7)$ & $897(63.4)$ & \\
\hline \multicolumn{5}{|l|}{ Child status } \\
\hline No CP & 1356 (96.7) & $2143(95.2)$ & 1329 (94.0) & \multirow{2}{*}{0.004} \\
\hline $\mathrm{CP}$ & $47(3.3)$ & $107(4.8)$ & $85(6.0)$ & \\
\hline \multicolumn{5}{|l|}{ Delivery mode } \\
\hline Vaginal delivery & $658(46.9)$ & $1148(51.0)$ & $698(49.4)$ & \multirow{2}{*}{0.053} \\
\hline Caesarean section & $745(53.1)$ & $1102(49.0)$ & $716(50.6)$ & \\
\hline \multicolumn{5}{|l|}{ Infant's sex } \\
\hline Girl (\%) & $672(47.9)$ & $1057(47.0)$ & $695(49.2)$ & \multirow{2}{*}{0.439} \\
\hline Boy (\%) & $731(52.1)$ & $1193(53.0)$ & $719(50.8)$ & \\
\hline \multicolumn{5}{|c|}{ Infant's birthweight (kg) } \\
\hline mean $\pm S D$ & $3.34 \pm 0.54$ & $3.14 \pm 0.71$ & $3.09 \pm 0.72$ & $<0.001$ \\
\hline
\end{tabular}

Table 4. Prevalence of SHS exposure in non-smoker pregnant mother and child, and OR (95\% CI) of CP according to mother's exposure to SHS during pregnancy, Shandong, 2017-2019 (N=5067)

\begin{tabular}{|c|c|c|c|c|c|}
\hline \multirow{2}{*}{$\begin{array}{l}\text { SHS exposure } \\
\text { (days/week) }\end{array}$} & \multirow{2}{*}{$\begin{array}{c}\text { Total } \\
n\end{array}$} & \multicolumn{2}{|c|}{ Child health status } & \multirow[t]{2}{*}{ OR (95\% CI) } & \multirow{2}{*}{ AOR $(95 \% \mathrm{CI})$} \\
\hline & & $\begin{array}{c}C P \\
n(\%)\end{array}$ & $\begin{array}{l}\text { No } C P \\
n(\%)\end{array}$ & & \\
\hline 0 (Ref.) & 1403 & $47(19.7)$ & $1356(28.1)$ & 1 & 1 \\
\hline $1-4$ & 2250 & $107(44.8)$ & $2143(44.4)$ & $1.44(1.02-2.04)$ & $1.46(1.13-1.91)$ \\
\hline $5-7$ & 1414 & 85 (35.5) & 1329 (27.5) & $1.85(1.28-2.66)$ & $1.63(1.22-2.01)$ \\
\hline All & 5067 & 239 & 4828 & $1.60(1.15-2.21)$ & $1.44(1.07-1.89)$ \\
\hline
\end{tabular}

OR: odds ratio. Cl: confidence interval. SHS: secondhand smoke. AOR: adjusted odds ratio, different exposure sources were adjusted mutually and for birthweight and delivery. $\mathrm{CP}$ : celebral palsy. 


\section{DISCUSSION}

Our study provides an insight into the association between maternal SHS exposure during pregnancy and children's CP. We found that SHS exposure during pregnancy was associated with an increased risk of CP. When we adjusted for confounding factors in the analysis, the exposure-outcome relationship remained statistically significant.

Tobacco use induces human disease and causes an economic burden worldwide ${ }^{10-12}$. SHS consists of $85 \%$ sidestream and $15 \%$ exhaled mainstream smoke ${ }^{13}$, hundreds of metal ingredients, and enduring harmful chemical gases suspended in the available breathing environment. A report from the US Centers for Disease Control and Prevention showed that nearly $50 \%$ of US non-smokers are exposed to $\mathrm{SHS}^{14}$, and there is no risk-free level of SHS exposure ${ }^{10,15}$. In developing countries, around $70 \%$ of men and $3 \%$ of women ${ }^{16}$ smoke. In China, the prevalence of active and passive smoking ${ }^{17}$ are both at high levels partly due to the failure of tobacco control enforcement measures in public areas. In our study, $4.7 \%$ of women smoked, and the SHS exposure prevalence of nonsmoker pregnant women was $72.3 \%$, which is a similar prevalence to that in Indonesia $(76 \%)^{18}$. We also found that women who live in rural areas and did not work had a higher prevalence of SHS exposure, which we hypothesize is closely related to their economic and educational level.

Passive inhalation of tobacco smoke and its byproducts could impact brain development and also increase the risk of dementia syndromes and mortality after stroke ${ }^{19,20}$. More than 41 million deaths among non-smoker adults and 400 deaths in infants are caused by exposure to SHS each year ${ }^{21}$. Consequences are very serious when a mother stays in the environment where tobacco smoke is present during pregnancy. Household wife's exposure to SHS is higher among younger individual $\mathrm{s}^{20}$, and our study also showed that younger people were more frequently exposed to SHS. Since most pregnant women, who constitute a vulnerable population, are aged $20-40$ years and typically spend more time indoors, it is not easy for them to avoid SHS exposure. Additionally, increased abdominal size and respiration, changes of immunologic systems and metabolic capacity ${ }^{22}$ of pregnant women may make them more sensitive than others to pollutants. Recently, studies found that SHS may represent a developmental neurotoxic during gestation ${ }^{23,24}$, and the brain's executive system can be ultimately influenced by neurotoxicity during critical periods in brain development ${ }^{19}$. A study reported that secondhand smoke can affect the central neuroexcitatory ${ }^{25}$. It is well established that mothers' smoking during pregnancy is associated with higher neurological risks in development and growth $^{26}$. There are many other noxious compounds in tobacco smoke that can cross the placental barrier and influence prenatal development ${ }^{27}$. A metaanalysis showed that women exposed to SHS during pregnancy is associated with higher risk of infants' neural tube defects ${ }^{28}$.

A systematic review ${ }^{29}$ reported several risk factors such as placental problems, birth defects, low birthweight, emergency caesarean section, respiratory distress syndrome, birth asphyxia, and neonatal infections etc., as significantly associated with CP. In our study, we found that SHS exposure during pregnancy increased the risk of children's CP compared with those without these exposures and the risk increased with the exposure time. Previous research has indicated an association between SHS and low birthweight ${ }^{30}$. Prenatal exposure to SHS has higher risk of stillbirth, congenital malformation ${ }^{31}$, and lower birthweight ${ }^{32-35}$. SHS exposure during pregnancy is associated with lower birthweight in our study, birthweight became lower when mothers were exposed to increasing doses of SHS, from unexposed to exposure 5-7 days/week; this can be another pathway from SHS to CP. We also found dose-response relations between increased risk of CP and duration of SHS exposure. We were unable to compare our results with the other studies because no previous studies on CP children evaluated the SHS exposure duration. Our study builds on the literature on SHS exposure during pregnancy to assess the setting-specific association between prenatal SHS exposure and children's CP.

Comprehensive tobacco control measures have been enacted in China these years, and the smoke-free areas were greatly extended to most indoor public places. However, a substantial proportion of pregnant women are still exposed to tobacco smoke where there is no smoking. Although multiple factors play a role in $\mathrm{CP}$, there remain some risk factors that can be circumvented through public health strategies. The 
prevention of SHS exposure represents a modifiable risk factor for preventing $\mathrm{CP}$.

\section{Strengths and limitations}

The strengths of our study are that we have a large sample size from three cities in Shandong Province, China and we explored the dose-response relationship between SHS exposure level and CP. Furthermore, self-assessment surveys by mothers were performed in hospital and clinical service departments in the community, so the data are more reliable when collected by professional neurosurgeons and pediatricians. However, potential limitations also need to be considered. First, this study was an observational study and is more likely to be affected by confounding factors; therefore, although we demonstrated that exposure to SHS during pregnancy possibly causes children's CP, we did not clinically measure exposure to SHS in this study. Second, our data may not be representative of all pregnant women in China. Third, although the strength of this study is the dose-response of SHS exposure, it is limited by self-report and may need biochemical measurements to ascertain further mechanisms.

\section{CONCLUSIONS}

Our study suggests an association between prenatal SHS exposure and CP. The finding enhances our understanding of other risk factors for CP and emphasizes the necessity to protect pregnant women and avoid CP. Actions should be implemented to reduce the harmful effects of SHS exposure in mothers and their babies during pregnancy.

\section{REFERENCES}

1. Caleyachetty R, Tait CA, Kengne AP, Corvalan G, Uauy $\mathrm{R}$, Echouffo-Tcheugui JB. Tobacco use in pregnant women: analysis of data from Demographic and Health Surveys from 54 low-income and middle-income countries. Lancet Glob Health. 2014;2(9):e513-e520. doi:10.1016/S2214-109X(14)70283-9

2. Al-Sayed EM, Ibrahim KS. Second-hand tobacco smoke and children. Toxicol Ind Health. 2014;30(7):635-644. doi:10.1177/0748233712462473

3. Giovino GA. The tobacco epidemic in the United States. Am J Prev Med. 2007;33(6 Suppl):S318-S326. doi:10.1016/j.amepre.2007.09.008

4. Pineles BL, Park E, Samet JM. Systematic review and meta-analysis of miscarriage and maternal exposure to tobacco smoke during pregnancy. Am J Epidemiol.
2014;179(7):807-823. doi:10.1093/aje/kwt334

5. Rogers JM. Tobacco and pregnancy. Reprod Toxicol. 2009;28(2):152-160. doi:10.1016/j.reprotox.2009.03.012

6. Humphrey A, Dinakar C. Maternal second-hand smoke exposure in pregnancy is associated with childhood asthma development. Pediatrics. 2014;134(Suppl 3):S145-S146. doi:10.1542/peds.2014-1817W

7. Dome P, Lazary J, Kalapos MP, Rihmer Z. Smoking, nicotine and neuropsychiatric disorders. Neurosci Biobehav Rev. 2010;34(3):295-342. doi:10.1016/j.neubiorev.2009.07.013

8. Barnett R. Cerebral palsy. Lancet. 2018;392(10147):545. doi:10.1016/s0140-6736(18)31702-1

9. Villamor E, Tedroff K, Peterson M, et al. Association Between Maternal Body Mass Index in Early Pregnancy and Incidence of Cerebral Palsy. JAMA. 2017;317(9):925936. doi:10.1001/jama.2017.0945

10. United States Office on Smoking and Health. 4 Prevalence of Exposure to Secondhand Smoke. The Health Consequences of Involuntary Exposure to Tobacco Smoke: A Report of the Surgeon General. Atlanta, GA: Centers for Disease Control and Prevention; 2006. https://www.ncbi.nlm.nih.gov/books/NBK44325/. Accessed March 10, 2020.

11. Chaouachi K. Hookah (Shisha, Narghile) Smoking and Environmental Tobacco Smoke (ETS). A critical review of the relevant literature and the public health consequences. Int J Environ Res Public Health. 2009;6(2):798-843. doi:10.3390/ijerph6020798

12. Sleiman M, Gundel LA, Pankow JF, Jacob III P, Singer BC, Destaillats H. Formation of carcinogens indoors by surface-mediated reactions of nicotine with nitrous acid, leading to potential thirdhand smoke hazards. Proc Natl Acad Sci U S A. 2010;107(15):6576-6581. doi:10.1073/pnas.0912820107

13. Schick S, Glantz S. Philip Morris toxicological experiments with fresh sidestream smoke: more toxic than mainstream smoke. Tob Control. 2005;14(6):396-404. doi:10.1136/tc.2005.011288

14. Disparities in secondhand smoke exposure--United States, 1988-1994 and 1999-2004. MMWR Morb Mortal Wkly Rep. 2008;57(27):744-747. https://www.cdc.gov/mmwr/ preview/mmwrhtml/mm5727a3.htm. Accessed March 10, 2020.

15. Oono IP, Mackay DF, Pell JP. Meta-analysis of the association between secondhand smoke exposure and stroke. J Public Health (Oxf). 2011;33(4):496-502. doi:10.1093/pubmed/fdr025

16. World Health Organization. WHO report on the global tobacco epidemic 2013: Enforcing bans on tobacco advertising, promotion and sponsorship. https://www. who.int/tobacco/global_report/2013/en/. Published 2013. Updated 2013. Accessed March 10, 2020.

17. Wang CP, Ma SJ, Xu XF, Wang JF, Mei CZ, Yang GH. The prevalence of household second-hand smoke exposure and its correlated factors in six 
counties of China. Tob Control. 2009;18(2):121-126. doi:10.1136/tc.2008.024836

18. Soesanti F, Uiterwaal C, Grobbee DE, Hendarto A, Dalmeijer GW, Idris NS. Antenatal exposure to second hand smoke of non-smoking mothers and growth rate of their infants. PLoS One. 2019;14(6):e0218577. doi:10.1371/journal.pone.0218577

19. Pagani LS. Environmental tobacco smoke exposure and brain development: the case of attention deficit/ hyperactivity disorder. Neurosci Biobehav Rev. 2014;44:195-205. doi:10.1016/j.neubiorev.2013.03.008

20. Lin MP, Ovbiagele B, Markovic D, Towfighi A. Association of Secondhand Smoke With Stroke Outcomes. Stroke. 2016;47(11):2828-2835. doi:10.1161/STROKEAHA.116.014099

21. US National Center for Chronic Disease Prevention and Health Promotion - Office on Smoking and Health. The Health Consequences of Smoking-50 Years of Progress: A Report of the Surgeon General. Atlanta, GA: US Centers for Disease Control and Prevention; 2014. https://www. ncbi.nlm.nih.gov/books/NBK179276/. Accessed March 10, 2020.

22. Wang L, Fu K, Li X, Kong B, Zhang B. Exposure to third-hand smoke during pregnancy may increase the risk of postpartum depression in China. Tob Induc Dis. 2018;16(April). doi:10.18332/tid/87141

23. Chen R, Clifford A, Lang L, Anstey KJ. Is exposure to secondhand smoke associated with cognitive parameters of children and adolescents?--a systematic literature review. Ann Epidemiol. 2013;23(10):652-661. doi:10.1016/j.annepidem.2013.07.001

24. Pagani LS, Fitzpatrick C. Prospective associations between early long-term household tobacco smoke exposure and antisocial behaviour in later childhood. J Epidemiol Community Health. 2013;67(7):552-557. doi:10.1136/jech-2012-202191

25. Middlekauff HR, Park J, Agrawal H, Gornbein JA. Abnormal sympathetic nerve activity in women exposed to cigarette smoke: a potential mechanism to explain increased cardiac risk. Am J Physiol Heart Circ Physiol. 2013;305(10):H1560-H1567. doi:10.1152/ajpheart.00502.2013

26. Cornelius MD, De Genna NM, Leech SL, Willford JA, Goldschmidt L, Day NL. Effects of prenatal cigarette smoke exposure on neurobehavioral outcomes in 10-yearold children of adolescent mothers. Neurotoxicol Teratol. 2011;33(1):137-144. doi:10.1016/j.ntt.2010.08.006

27. US Office on Smoking and Health. 5 Reproductive and Developmental Effects from Exposure to Secondhand Smoke. The Health Consequences of Involuntary Exposure to Tobacco Smoke: A Report of the Surgeon General. Atlanta, GA: US Centers for Disease Control and Prevention; 2006. https://www.ncbi.nlm.nih.gov/books/ NBK44317/. Accessed March 10, 2020.

28. Meng X, Sun Y, Duan W, Jia C. Meta-analysis of the association of maternal smoking and passive smoking during pregnancy with neural tube defects. Int J Gynaecol Obstet. 2018;140(1):18-25. doi:10.1002/ijgo.12334

29. McIntyre S, Taitz D, Keogh J, Goldsmith S, Badawi $\mathrm{N}$, Blair E. A systematic review of risk factors for cerebral palsy in children born at term in developed countries. Dev Med Child Neurol. 2013;55(6):499-508. doi:10.1111/dmcn.12017

30. Hoyt AT, Canfield MA, Romitti PA, et al. Does Maternal Exposure to Secondhand Tobacco Smoke During Pregnancy Increase the Risk for Preterm or Small-for-Gestational Age Birth? Matern Child Health J. 2018;22(10):1418-1429. doi:10.1007/s10995-018-2522-1

31. Leonardi-Bee J, Britton J, Venn A. Secondhand smoke and adverse fetal outcomes in nonsmoking pregnant women: a meta-analysis. Pediatrics. 2011;127(4):734741. doi:10.1542/peds.2010-3041

32. Leonardi-Bee J, Smyth A, Britton J, Coleman T. Environmental tobacco smoke and fetal health: systematic review and meta-analysis. Arch Dis Child Fetal Neonatal Ed. 2008;93(5):F351-F361. doi:10.1136/adc.2007.133553

33. Peacock JL, Cook DG, Carey IM, et al. Maternal cotinine level during pregnancy and birthweight for gestational age. Int J Epidemiol. 1998;27(4):647-656. doi:10.1093/ije/27.4.647

34. Salmasi G, Grady R, Jones J, McDonald SD, Knowledge Synthesis Group. Environmental tobacco smoke exposure and perinatal outcomes: a systematic review and metaanalyses. Acta Obstet Gynecol Scand. 2010;89(4):423441. doi:10.3109/00016340903505748

35. Windham GC, Eaton A, Hopkins B. Evidence for an association between environmental tobacco smoke exposure and birthweight: a meta-analysis and new data. Paediatr Perinat Epidemiol. 1999;13(1):35-57. doi:10.1046/j.1365-3016.1999.00150.x

\section{ACKNOWLEDGEMENTS}

Thanks to Rui Wang-Sattler and Qi Pang for assisting with the literature and statistical analyses.

CONFLICTS OF INTEREST

The authors have completed and submitted the ICMJE Form for Disclosure of Potential Conflicts of Interest and none was reported.

\section{FUNDING}

This work was supported by the Study Abroad Program Foundation of Shandong Government, No. 201801005.

PROVENANCE AND PEER REVIEW

Not commissioned; externally peer reviewed. 